\title{
An Analysis on Social Unstable Factors of the Urban New Poverty Group
}

\author{
Liu Yutong* \\ National Police University of China \\ Shen Yang, China \\ (13705040@qq.com)
}

\author{
Ding Yong \\ National Police University of China \\ Shen Yang, China \\ (yong.ding@foxmail.com)
}

\begin{abstract}
With the China's reform and opening up, and the social, economical and industrial transformation, the amount of urban laid-off workers and rural migrant workers is increasing rapidly. As the social management and security system development are lagging behind, the gap between the rich and the poor in the city keeps on widening, and urban new poverty problem becomes increasingly serious which is harmful to urban public security and social stability. In order to explore the solution to the unstable problem on the next step, the essay aims to conclude the unstable reasons of the urban new poverty comprehensively and objectively, which include social environment factors from the objective perception and the group psychology factors from the subjective perception.
\end{abstract}

Keywords—urban new poverty; unstable factors; social stability; transition

\section{INTRODUCTION}

Urban poverty is always the outstanding problem during the urbanization process at home and abroad which has drawn great attention of scholars. In the process of rapid urbanization of our country, urban new poverty problem becomes so serious to affect the urban social stability and development that the research on the problem has stronger realistic urgency. The existing researching literatures about the urban new poverty group is mainly about the formation background and definition indicators, and gradually focus on the correlation between urban new poverty and the social stability.

\section{A. The transformation of the researching perspective on the urban new poverty problem}

It is widely believed that Rowntree, a British economist, is the first scholar to research poverty problem systematically, who had written a book named "poverty: a study of urban life" in 1901 took a town named York as sample. With the continuous development of society, the connotation and denotation of the poverty have also change, so as to the focus of the government, social and academic on poverty. That is: from focus on "lack of money" simply to focus on "internal causes" about the abilities, psychology and so on, and focus on "external causes" about deprivation and social exclusion [1]. The perspective has transformed from single to multidimensional one, from individual, familial and other microscopic one to social system and structure of macro one.

\section{B. The transformation of the identification perspective on urban new poverty group}

With the transformation of urban new poverty research perspective, the criterion of identification for poverty has changed, so did the specific indicator which has changed from the single to the multidimensional one. Firstly, According to the criterion of identification, the urban new poverty is a kind of relative rather than absolute poverty [2]. Absolute poverty means the people's consumption ability and rights can not afford their lives. While relative poverty refers to that people's income can satisfy their basic survival needs, but Fail to meet the minimum standard of living in the society they live; Secondly, the specific indicator of identification for urban new poverty transform from income in a single to a multidimensional indicator system, such as "poverty for living, rights and interests, happiness" [3], etc.

\section{The urban new poverty and social stability}

There is a large amount of analysis and researches on the correlation between the urban new poverty group and social stability. The existing researches in our country can be mainly summarized the following three points: (1) The sense of relative deprivation in the urban new poverty group produced by gap of wealth may result in serious social discontent and group antagonism [4], that is easy to cause security problems such as mass incidents; (2) The lack of approaches to realize the aspirations and interests for the disadvantaged groups such as the land-lost farmers may directly cause them to choose abnormal way to express their interests appeal [5]; (3) Social exclusion to the urban new poverty could result in their psychological causes, which in turn lead to serious adverse social consequences.

\section{THE IDENTIFICATION AND CHARACTERISTICS}

Since the mid 1990s, the transformation of economy and society has brought new time and space dimension to China's urban poverty problem which is harmful for social stability. It is theoretically and practically significant to analyze the unstable factors of the urban new poverty that could cause social problems. 
A.Transition poverty: the definition and formation of the urban new poverty group

The current urban new poverty is distinctively different from the traditional poverty, therefore, there are two factors in identifying the urban new poverty group: The first one is "living space" that refers to whether the poverty group is living in city and engaged in non-agricultural industry. The second one is "time background" that refers to whether the poverty is produced in the transitional period, therefore, the urban new poverty in our country is a kind of "transitional poverty" from macro perspective of "transformation" which includes the economic transformation and social transformation. The economic transformation is a multidimensional concept which consists of transformation of economic system, as well as that of economic structure, technical structure, market structure, enterprise organization structure and so on. The social transformation refers to the transition from traditional society to modern society, and characterized by the three aspects: social structure, social operation mechanism, and value system. The urban new poverty formed in the period of economic system reform, and has been continuously developed with the urbanization process.

In view of this, the urban new poverty group should include not only the laid-off workers who appeared in large quantity at the end of the 20th century, but also the urban underprivileged groups such as rural migrant workers, the land-losing farmers and so on who formed in the urbanization process. They are the urban new poverty in "transition" because that they all live in cities and work in the second or third industry and have outstanding characteristic of social and economic institutional change and transformation.

$B$. Relative poverty: the nature and criterion of the urban new poverty group

In our country, the nature of the current urban new poverty is relative poverty. Generally speaking, this group can afford their basic lives, but their living standard is much lower than the average. In view of this, economic income is no longer the single indicator to confine relative poverty. The urban new poverty could be identified by an index system consists of three indicators as material poverty, rights poverty and mental poverty (Table I ).

Table I : Index System for the Urban New Poverty

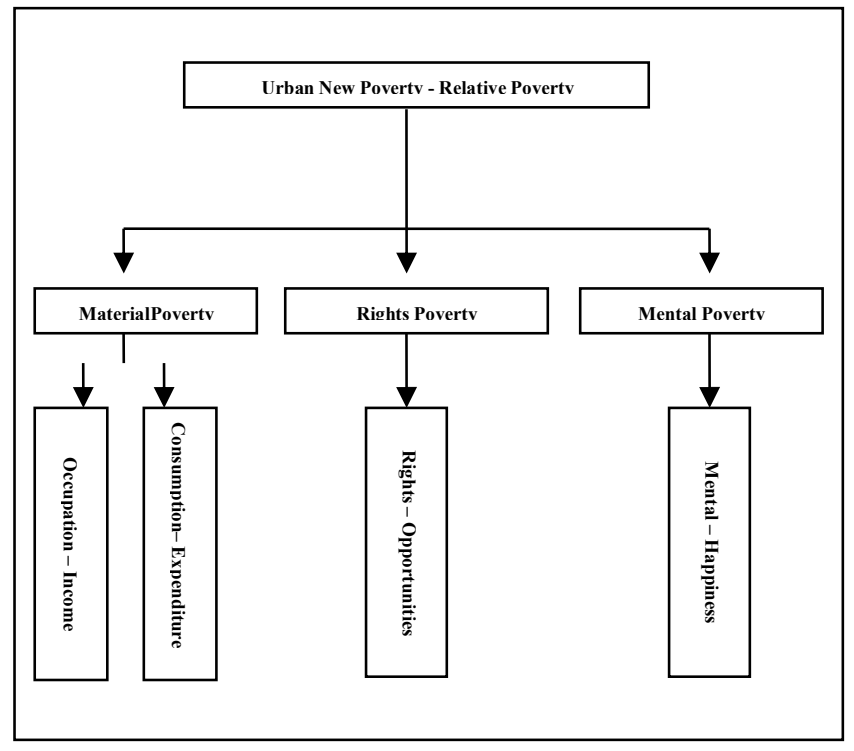

1) Material poverty can be observed through occupation income and consumption - expenditure. From the perspective of occupation-income, the urban new poverty group is mainly composed of urban laid-off workers, rural migrant workers and land-lost farmers. They usually lack of cultural knowledge, re-employment abilities, business skills so that it is hard for them to obtain re-employment or stable employment chance, and can only get some temporary jobs as low- technical content, low-payment or become low-income street vendors; From the perspective of consumption-expenditure, the consumption of the urban new poverty group is passive and low because of their low income. The expenditure of the group include housing, educational, medical and other necessary expenses in addition to the main content of basic survival needs such as clothing, food, etc.. Usually speaking, the group could make ends meet because of the expenditure of family health and children's education, so that they would have little money for initiative and entertainment consumption.

2) Rights poverty is mainly from the perspective of rights - opportunities, the urban new poverty group is underclass who is disadvantaged not only in economic resources but in social resources, social mobility, welfare policy, rights for interest expression and so on.

3) Mental poverty is mainly from the perspective of psychological - happiness, due to the disadvantaged position and the lack of chance resources, the urban new poverty group has a strong sense of injustice, inferiority and social exclusion, their sense of relative deprivation is stone but happiness is weak. They are easy to have antagonism for the upper and middle class groups in society as a result of the psychological sense.

\section{III.THE INFLUENCE OF THE URBAN NEW POVERTY GROUP ON SOCIAL STABILITY}

In the $1990 \mathrm{~s}$, as the transformation of the economic and social structure and the speeding up of urbanization, China's urban poverty population was growing rapidly. The amount of the urban poverty has increased by almost five times in ten years which has become one of the most serious social problems. The rapid increase of the amount of new poverty group and the continuous enlargement of the gap between rich and poor put forward more and higher demands on social welfare, assistance, guidance and support system on one hand, and also potentially harm the harmonious and stability of the society on the other hand.

\section{A.Influence on social order}

Owing to the unequal opportunities for urban new poverty group, the wealth gap between rich and poor keeps on enlarging, and the direct result is group opposing in the society. As we know, if the large income gap between the laborers cannot be eliminated or reduced by normal working, the poor in city would feel difficult to change the state of poverty even abandon to try to improve their abilities to increase their income, which could make negative effect to the social order. More seriously, as the wealth gap is too big to be tolerated by the society, the poverty group might feel anxiety and insecure of the existing social order, and might attempt to change the existing status, which is harmful for social stability. 


\section{B.Influence on economic order}

Once the logic of "If it is hard to get rich reasonably and legally, why not try the unreasonable and illegal ways?" generated among the urban new poverty, some of then would inevitably let off steam and find out unreasonable or even illegal ways to get wealthy. As a result, the economic order and chaos will get worse and orderly market environment cannot be formed.

\section{Influence on political order and reform process}

The continued increasing poverty and enlarging wealth gap could reduce the public support for the government and the reform, and weaken the government control or lead to social disorder.

\section{IV.ANALYSIS ON THE SOCIAL STABILITY CAUSES OF POVERTY GROUPS}

The urban new poverty is one of the most important problems during China's economic and social transformation, it would negatively impact the social stability as well as the reform and opening up process if not controlled effectively and timely [6]. It is urgent to analyze the potential unstable causes of the urban new poverty to base for exploring the effective means of social control next. Usually deviant behavior is the result of the interaction between social environment and behavior subject, so we could analyze social unstable causes of urban poverty group from the two aspects of objective social environment factors and the subjective group psychological factors.

\section{A.Objective perspective: analysis on the social environment factors}

\section{1) Social structure stress}

Robert King Merton, American sociologist, argued that social culture has proposed goals accepted and desired by the society (e.g., to become successful in the money), and also made clear the legal means or social acceptance means to achieve these goals (such as working hard working, studying diligently). If the arrangement of social structure cannot provide legal means to achieve these goals for people, it would naturally make them feel frustrated and nervous, the situation is called social structure stress. Under the background of the rapid social transformation in our country, the urban new poverty group has fewer abilities, rights and other resources, has little or no chance to achieve success target set by social culture through the legal ways. The Frustration and tension could make some of the urban new poverty to choose illegal means (deviant behavior) that threaten social stability in order to obtain the legal goal, such as theft, robbery crime; or simply give up the legitimate targets and the normal life of the society, such as alcoholism, drug abuse, suicide, etc. From a certain extent, the deviant behavior of the urban new poverty is a result of the social structure stress because in their real life they cannot achieve goals with legal means of cultural.

\section{2) The weakening of social control function}

Social transition in China since reform and opening up is a kind of transformation from a highly centralized planned economy to the market economic society. Along with the transformation from the old to the new, the society is easy to be disorder in the process of running and the social control function becomes weaken or even failure. In this situation, the social members would feel disoriented, and there would be more and more frictions and contradictions between people and groups such as various land disputes, debt disputes and group conflict.

For the laid-off workers in the 1990s, the sudden lost of controls, rules, benefits rights and so on in the system made them at loose ends and have the fight mood and behavior; For rural migrant workers, most of them are experiencing a passive process of urbanization, so the rapid development of urbanization makes them by surprise. The dual system of urban and rural restricts their upward mobility, related social security and rights policy failed to come on stage, their social integration degree is low, and the urban floating population management system is not perfect, etc., all these fact have made this group to become the urban unstable factors.

3) The pressure from large number of floating population in the process of rapid urbanization

With the deepening rapid urbanization of China's, the crime rate of urban floating population keeps high, especially for serious crime cases in which $70 \%$ of the subject belongs to floating population [7]. The "China's floating population development report 2014", issued by National Health and Family Planning Commission, pointed out that in recent years, the scale of the floating population increase gradually, the floating population has reached 245 million which is more than $1 / 6$ of the total population at the end of 2013.

The large number of floating population in city can inevitably cause enormous pressure to the urban public security. The current floating population in city characterized by large size, high flowing speed and strong anonymity could increase the difficulty of the social management, because there are often many fugitive suspects and unstable molecules hidden who may commit crime at any time.

Population explosion may cause tensions in employment opportunities because that the rural surplus labor force is far more than the employment capacity in cities. Generally speaking, the rural surplus laborers have much less opportunity to get jobs in the city than the urban population, as a result they are often engaged in low-level physical labor or service industry in which some of them even conduct illegal activities such as prostitution, many of them become part of the "street" labor who often peddle food and service unregistered, and bring great instability to urban society.

4) Channels of interests expression is not clear

Having little or no chance to express and realize their appeal and interests is one of the important reasons for the urban new poverty group to take deviant behaviors. Due to the stress of inefficient or even invalid institutionalized expression, someone of the group often choose abnormal ways such as petitions, group events to express their interest demands and seek response from the related institutions. 
B. Subjective perspective: analysis on the group psychological factors

1) Sense of relative deprivation

Robert King Merton argued that when individuals compared their own situation with a standard or an object (reference group), and found themselves at a disadvantage, they will feel deprived. And the feeling of deprivation will produce negative emotions such as discontent, anger or resentment. Because of the differences in possession of social resources, the urban new poverty group has already become dissatisfied with the relatively high status groups. The situation should be efficiently controlled in order to avoid increasing fierce antagonism and conflict between groups, and to keep the harmony and stability of the society.

\section{2) Marginal psychology}

Due to the dual system of city and countryside and the aboriginal exclusion from the urban residents, it is difficult for the urban migrants from countryside to Integrated into the city life. There is a strong sense of exclusion and discrimination among the migrants generally that makes them feel anxiety and discontent, as a result they might not only easily to have antagonistic behavior, but also lack of self-discipline and control even to abandoned themselves .

\section{3) Frustration}

Aggressive behaviors are often caused by the frustration, which depends on the degree of dissatisfaction with the realization of one's needs, impulses and desires. When the urban new poverty group failed to meet their demands such as lacking of economical security, political rights, self-realization and social belonging and so on, they would feel frustrated and take aggressive behavior. The extent of the aggressive behaviors depends on the frustration extent people suffered, that is to say the more people feel frustrated the easier for them to take aggressive behaviors.

\section{V.CONCLUSION}

Since the mid 1990s, as the deepening of the Industrialization and urbanization in China, the urban poverty has developed rapidly than ever which brings unstable factors to the society. The study primarily analyzes the factors of the urban new poverty group which cause social instability and mainly comes to the conclusion as follows:

(1) The urban poverty is a kind of relative poverty produced in the transitional period. The urban new poverty group should include not only the laid-off workers who appeared in large quantity at the end of the 20th century, but also the urban underprivileged groups such as rural migrant workers, the land-losing farmers and so on who formed in the urbanization process.

(2) The rapid increase of the amount of new poverty group and the continuous enlargement of the gap between rich and poor potentially harm the harmonious and stability of the society. The urban new poverty problem has influence on social order, economic order, political order and reform process.

(3) The study analyzes social unstable causes of urban poverty group from the two aspects of objective social environment factors and the subjective group psychological factors. From the objective perspective, there may be at least four causes that make the urban new poverty group to become unstable: social structure stress, weakening of social control function, pressure from large number of floating population in the process of rapid urbanization and channels of interests expression is not clear. From the subjective perspective, the psychological states of marginal psychology, sense of relative deprivation as well as frustration are widespread in the urban new poverty which would lead to deviant behaviors.

From what has been discussed above, the urban new poverty would negatively impact the social stability as well as the reform and opening up process if not controlled effectively and timely, so it is necessary to explore effective approaches to solve the problem

\section{ACKNOWLEDGMENT}

The author would like to express my gratitude to all those who helped me during the writing of this thesis. This study was partially supported by the Social Science Foundation of Liaoning Province, China (Grant No. L14BSH011), the Public Security Theory and Soft Science Research Plan from Ministry of Public Security of China (Grant No.2014LLYJXJXY011).

\section{REFERENCES}

[1] Dang Chunyan, "Reach on urban poverty in our country in transition", Shanghai: Central China Normal University, 2013. (In Chinese)

[2] Amartya Sen, Poverty and Hunger. Beijing: the Commercial Press, 2001. (In Chinese)

[3] Xie Lvyuan and Song Feng, "Study on social harm and its countermeasures of the urban new poverty," Science and Technology, 2014 (8). (In Chinese)

[4] Zhao Lun, "Relative poverty from individual attribution to social deprivation," Business Times, 2014 (18) . (In Chinese)

[5] Zheng Tao, "Research on interests appeal problems of land-losing farmers in urbanization, Shanghai: East China normal university, 2013. ( In Chinese)

[6] Yin Zhigang, "Analysis urban poor products cause Beijing, Journal of Marketing and Demographic analysis, 2002 (4). (In Chinese)

[7] Wu Pengsen, Criminal Sociology, Beijing : Social Sciences Academic Press, 2008. (In Chinese) 